\title{
Carbono, matéria orgânica leve e fósforo remanescente em diferentes sistemas de manejo do solo
}

\author{
Marcos Gervasio Pereira ${ }^{(1)}$, Arcângelo Loss ${ }^{(1)}$, Sidinei Júlio Beutler ${ }^{(1)}$ e José Luis Rodrigues Torres(2)
}

\begin{abstract}
(1)Universidade Federal Rural do Rio de Janeiro, Departamento de Solos, BR 465, Km 7, CEP 23890-000 Seropédica, RJ. E-mail: gervasio@ufrrj.br, arcangeloloss@yahoo.com.br, s.parana@yahoo.com.br ${ }^{(2)}$ Instituto Federal de Educação, Ciência e Tecnologia Triângulo Mineiro, Campus Uberaba, Avenida Edilson Lamartine Mendes, no 300, CEP 38045-000 Uberaba, MG. E-mail: jIrtorres@cefetuberaba.edu.br
\end{abstract}

Resumo - O objetivo deste trabalho foi avaliar os teores de carbono orgânico total (COT), matéria orgânica leve (MOL) e fósforo remanescente (Prem), em áreas de cerrado sob sistema de plantio direto com diferentes cultivos de coberturas do solo, e compará-los aos de áreas sob preparo convencional e pousio. O experimento foi conduzido em campo, em um Latossolo Vermelho, de agosto de 2000 a março de 2007. O delineamento utilizado foi o de blocos ao acaso com parcelas subdivididas, sendo as parcelas constituídas pelos cinco sistemas de manejo do solo avaliados - pousio, preparo convencional e plantio direto com uso dos cultivos de cobertura crotalária (Crotalaria juncea), milheto (Pennisetum americanum) e braquiária (Urochloa brizantha) -, e as subparcelas pelos cultivos de soja e milho. Em março de 2007, coletaram-se amostras de solo das profundidades $0,0-0,025,0,025-0,05,0,05-0,10$ e $0,10-0,20 \mathrm{~m}$, das quais foram quantificados COT, MOL, estoques de COT e Prem. Em áreas sob plantio direto, o aumento nos teores de MOL pode reduzir a adsorção de fósforo ao solo. Sistemas de manejo que não envolvem revolvimento do solo favorecem o aumento do estoque de carbono orgânico nas camadas superficiais, enquanto o preparo convencional e o plantio direto com uso do milheto como planta de cobertura propiciam a incorporação mais profunda do carbono.

Termos para indexação: Cerrado, estoque de carbono, plantas de cobertura, plantio direto, pousio, preparo convencional.

\section{Carbon, light organic matter and remaining phosphorus in different soil management systems}

\begin{abstract}
The objective of this study was to evaluate the contents of total organic carbon (COT), light organic matter (MOL) and remaining phosphorus (Prem) on savanna areas under no tillage system using cover crops and to compare them to the ones observed under fallow and conventional tillage. The experiment was carried out in field conditions, in a Latossolo Vermelho (Rhodic Haplustox) from August 2000 to March 2007. A randomized complete block design was used, in a split-plot arrangement, with plots consisting of the five soil management systems evaluated - fallow, conventional tillage, and no tillage using sunn hemp (Crotalaria juncea), pearl millet (Pennisetum americanum), and palisade grass (Urochloa brizantha) as cover crops -, and sub-plots consisting of maize and soybean crops. In March 2007, the $0.0-0.025,0.025-0.05,0.05-0.10$ e $0.10-0.20 \mathrm{~m}$ soil layers were sampled and assessed for COT, MOL, COT stocks and Prem. In the no tillage areas, increases in MOL content can reduce phosphorus adsorption in soil. Management systems without soil disturbance increases COT stocks in the superficial layers while conventional tillage and no tillage using pearl millet as cover crops provide a deeper incorporation of carbon in the soil.
\end{abstract}

Index terms: Cerrado, carbon stocks, cover crops, no tillage, fallow, conventional tillage.

\section{Introdução}

O bioma Cerrado é o segundo maior em extensão geográfica, apresenta acentuada sazonalidade e interferência antrópica (Sano et al., 2007) e é, também, uma das maiores áreas cultivadas do mundo (Siqueira Neto et al., 2009). No Estado de Minas Gerais, áreas de cerrado correspondem a $57 \%$ da área total e apresentam mais de 2 milhões de hectares sob cultivo (Sano et al., 2008). A conversão de áreas de cerrado em áreas de cultivo, com derrubada e queima da vegetação natural, pode reduzir os teores da matéria orgânica do solo (MOS), acarretar a perda de fertilidade e o aumento da erosão (Bernoux et al., 2004).

Os sistemas de manejo do solo, associados a certas práticas agrícolas, como rotação de culturas e cultivos

Pesq. agropec. bras., Brasília, v.45, n.5, p.508-514, maio 2010 
de cobertura, promovem alterações significativas na dinâmica da MOS (Moreti et al., 2007; Brancalião \& Moraes, 2008; Loss et al., 2009). Estudos recentes têm destacado o efeito benéfico de plantas de cobertura nas propriedades edáficas e no rendimento de culturas, decorrentes da ciclagem de nutrientes e da decomposição da palhada (Bertin et al., 2005; Boer et al., 2007; Torres et al., 2008).

Parte da MOS é composta pela matéria orgânica leve (MOL), que é uma fração ativa no solo, constituída por resíduos orgânicos parcialmente humificados em vários estádios de decomposição, com tempo de residência no solo que varia de um a cinco anos (Janzen et al., 1992). Além de ser constituída, principalmente, de partes de plantas, a MOL pode apresentar resíduos de animais e microrganismos em diversos estádios de decomposição.

As principais características do solo que influenciam a adsorção de P são: mineralogia das argilas, o conteúdo de coloides amorfos não cristalinos e o teor de matéria orgânica (Novais \& Smyth, 1999). O fósforo remanescente (Prem) é uma medida estreitamente correlacionada à capacidade máxima de adsorção e à capacidade tampão de fosfatos (Alvarez \& Fonseca, 1990; Novais \& Smyth, 1999; Almeida et al., 2003). Fontana et al. (2008) avaliaram a correlação entre Prem e as frações da MOS, em um Latossolo Vermelho distroférrico com sucessão soja/aveia e verificaram que os sistemas de manejo em plantio direto (PD) reduziram a adsorção e a precipitação de $\mathrm{P}$, principalmente pela presença de substâncias húmicas mais estáveis, como ácidos húmicos e humina.

A MOS desempenha papel ambivalente em relação à disponibilidade de $\mathrm{P}$, já que tanto pode adsorvê-lo quanto bloquear os sítios de adsorção que ocorrem nas superfícies das argilas e óxidos de ferro e alumínio (Ibia \& Udo, 1993). A adoção de sistemas de manejo que propiciem um incremento no teor de MOS ou de suas frações pode promover a redução da adsorção de $\mathrm{P}$, pela formação de complexos que bloqueiam os sítios de adsorção na superfície dos óxidos de ferro e de alumínio (Tirloni et al., 2009). Assim, o uso de plantas de cobertura em SPD pode acarretar aumento dos teores de carbono orgânico total (COT) e MOL e, consequentemente, diminuir a adsorção de fosfatos e favorecer os teores de Prem.

Apesar de na literatura serem encontrados dados sobre os teores e estoques de carbono orgânico, em solos cultivados no Cerrado (Bayer et al., 2004; Wendling et al., 2005; Corbeels et al., 2006; Blanchart et al., 2007; Siqueira Neto et al., 2009), ainda são necessárias mais informações sobre os teores de MOS e os valores de Prem em experimentos de longa duração com uso de plantas de cobertura.

O objetivo deste trabalho foi avaliar os teores de carbono orgânico total, matéria orgânica leve e de fósforo remanescente, em ambiente de cerrado sob sistema de plantio direto com uso de plantas de cobertura, e comparar esses dados aos de áreas com preparo convencional e pousio.

\section{Material e Métodos}

A área experimental localiza-se no Centro Federal de Educação Tecnológica de Uberaba (Cefet), no Município de Uberaba, MG, (19³9'19"S, 4757'27"W, altitude de $795 \mathrm{~m}$ ). A precipitação média anual é de $1.600 \mathrm{~mm}$; a temperatura média anual é de $22,6^{\circ} \mathrm{C}$, e a umidade relativa do ar média é de $68 \%$. O clima é classificado, segundo Köppen, como Aw: verões quentes e úmidos e inverno frio e seco. O solo da área experimental foi classificado como Latossolo Vermelho distrófico típico (Santos et al., 2006). Antes da implantação do experimento, a camada superficial $(0-20 \mathrm{~cm})$ do solo apresentava os seguintes atributos: 180,50 e $770 \mathrm{~g} \mathrm{~kg}^{-1}$ de argila, silte e areia, respectivamente; $\mathrm{pH}_{\mathrm{H}_{2} \mathrm{O}}(1: 2,5), 6,3 ; 17 \mathrm{mg} \mathrm{dm}^{-3}$ de $\mathrm{P}$; $96 \mathrm{mg} \mathrm{dm}^{-3}$ de K; $1,9 \mathrm{cmol}_{\mathrm{c}} \mathrm{dm}^{-3} \mathrm{de} \mathrm{Ca}^{2+} ; 0,6 \mathrm{cmol}_{\mathrm{c}} \mathrm{dm}^{-3}$ de $\mathrm{Mg}^{2+} ; 2 \mathrm{cmol}_{\mathrm{c}} \mathrm{dm}^{-3}$ de $\mathrm{H}+\mathrm{Al}$ e $16 \mathrm{~g} \mathrm{dm}^{-3}$ de matéria orgânica (Claessen, 1997).

O delineamento utilizado foi o de blocos ao acaso, com parcelas subdivididas. As parcelas foram constituídas pelas áreas de pousio, preparo convencional e plantio direto com uso de três diferentes plantas de cobertura: crotalária (Crotalaria juncea), milheto (Pennisetum americanum syn. typhoides), braquiária (Urochloa brizantha cv. Xaraés). O experimento foi instalado em agosto de 2000 , com quatro repetições, num total de 20 parcelas de $10 \mathrm{~m}^{2}$. As subparcelas foram constituídas pelo cultivo de milho ou de soja.

$\mathrm{Na}$ área de pousio, foi feita a identificação das plantas invasoras, noinício do experimento, tendo-se constatado a presença das seguintes famílias: gramíneas, em maior proporção, Solanacea, Compositae, Portulacacea, Cyperacea, Rubiacea e Amaranthacea. 
Aproximadamente 110 dias após o plantio (DAP), as plantas de cobertura foram dessecadas com $1.440 \mathrm{~g} \mathrm{ha}^{-1}$ de glifosato e $600 \mathrm{~g} \mathrm{ha}^{-1}$ de Paraquat. Posteriormente, em novembro de 2000, foram plantados o milho (Zea mays), híbrido duplo AG 1051, e a soja (Glycine max) MG/BR-46, tendo sido feitos os tratamentos das sementes e o controle de pragas, doenças e plantas daninhas durante o ciclo das culturas.

Logo após a colheita do milho e da soja, no final de março de 2001, foi feito, nos mesmos locais do ano anterior, o plantio das plantas de cobertura, que foram dessecadas aos 110 DAP, em julho de 2001. A partir de então, as áreas permaneceram em pousio até novembro de 2001. Nessa data, foi novamente feito o plantio das culturas de milho e soja. Esse procedimento foi realizado continuamente desde a implantação do experimento, em agosto de 2000, até março de 2007.

Para a adubação de plantio do milho, utilizaram-se $32 \mathrm{~kg} \mathrm{ha}^{-1}$ de $\mathrm{N}, 80 \mathrm{~kg} \mathrm{ha}^{-1}$ de $\mathrm{P}_{2} \mathrm{O}_{5}, 80 \mathrm{~kg} \mathrm{ha}^{-1}$ de $\mathrm{K}_{2} \mathrm{O}$ e $1,2 \mathrm{~kg} \mathrm{ha}^{-1}$ de Zn. Em cobertura, aplicaram-se $90 \mathrm{~kg} \mathrm{ha}^{-1}$ de $\mathrm{N}$ na forma de ureia, aos 10 dias após emergência (DAE), e mais $20 \mathrm{~kg} \mathrm{ha}^{-1}$ de $\mathrm{N}$ na forma de sulfato de amônia, aos 25 DAE. Para a cultura da soja, utilizaramse $8 \mathrm{~kg} \mathrm{ha}^{-1}$ de $\mathrm{N}, 80 \mathrm{~kg} \mathrm{ha}^{-1}$ de $\mathrm{P}_{2} \mathrm{O}_{5}, 80 \mathrm{~kg} \mathrm{ha}^{-1}$ de $\mathrm{K}_{2} \mathrm{O}$ e $1,2 \mathrm{~kg} \mathrm{ha}^{-1}$ de $\mathrm{Zn}$. Essas adubações foram realizadas durante todo período do experimento.

Em março de 2007, subamostras de solo foram coletadas aleatoriamente em dez locais, nas camadas de $0-0,025,0,025-0,05,0,05-0,10$ e $0,10-0,20 \mathrm{~m}$ de profundidade, para obtenção de uma amostra composta de profundidade. Na avaliação do estoque de carbono no solo (EstCOT), as amostras foram coletadas nas mesmas camadas, com o auxílio de espátula, em minitrincheiras de $0,2 \times 0,4 \mathrm{~m}$, transversais às linhas de semeadura. As amostras foram secas ao ar e tamisadas a $2 \mathrm{~mm}$.

Foram determinados os teores de carbono orgânico total (COT), por meio da oxidação da matéria orgânica pelo dicromato de potássio a $0,2 \mathrm{~mol} \mathrm{~L}^{-1} \mathrm{em}$ meio sulfúrico e pela titulação por sulfato ferroso amoniacal a $0,1 \mathrm{~mol} \mathrm{~L}^{-1}$ (Claessen, 1997). A matéria orgânica leve em água (MOL) foi separada pelo método da flotação em água (Anderson \& Ingram, 1989). A determinação da densidade do solo (Ds) foi feita pelo método do anel volumétrico (Claessen, 1997).

Para o cálculo do estoque de carbono total (EstCOT) no solo foi utilizado o método de massa equivalente (Ellert \& Bettany, 1995; Sisti et al., 2004), conforme a equação:

$$
\text { EstCOT }=\sum_{\mathrm{i}=1}^{\mathrm{n}-1} \mathrm{C}_{\mathrm{Ti}}+\left[\mathrm{M}_{\mathrm{Tn}}-\left(\sum_{\mathrm{i}=1}^{\mathrm{n}} \mathrm{M}_{\mathrm{Ti}}-\sum_{\mathrm{i}=1}^{\mathrm{n}} \mathrm{M}_{\mathrm{Si}}\right)\right] \mathrm{C}_{\mathrm{Tn}}
$$

em que:

EstCOT, é o estoque total de carbono $\left(\mathrm{Mg} \mathrm{ha}^{-1}\right)$ no solo para uma profundidade equivalente a mesma massa do solo escolhida do perfil de referência;

$\sum_{\mathrm{i}=1}^{\mathrm{n}-1} \mathrm{C}_{\mathrm{Ti}}$ é o somatório do carbono da primeira à penúltima camada ( $\mathrm{n}-1)$ no perfil avaliado $\left(\mathrm{Mg} \mathrm{ha}^{-1}\right)$; $\sum_{\mathrm{i}=1}^{\mathrm{n}} \mathrm{M}_{\mathrm{Si}}$ é o somatório da massa do solo da primeira à última camada no perfil avaliado $\left(\mathrm{Mg} \mathrm{ha}^{-1}\right)$; $\sum_{\mathrm{i}=1}^{\mathrm{n}} \mathrm{M}_{\mathrm{Ti}}$ é o somatório da massa do solo da primeira à última camada no perfil de referência $\left(\mathrm{Mg} \mathrm{ha}^{-1}\right) ; \mathrm{M}_{\mathrm{Tn}}$ é a massa do solo na última camada do perfil avaliado $\left(\mathrm{Mg} \mathrm{ha}^{-1}\right) ; \mathrm{C}_{\mathrm{Tn}}$ é a concentração de carbono na última camada do perfil avaliado ( $\mathrm{Mg}$ de $\mathrm{C} \mathrm{Mg}^{-1}$ de solo). A área (tratamento) de referência foi a de braquiária devido a menor massa de solo.

O fósforo remanescente (Prem) foi determinado conforme Alvarez \& Fonseca (1990). Cinco centímetros cúbicos de terra fina seca ao ar foram colocados em contato por uma hora com uma solução de $0,01 \mathrm{~mol} \mathrm{~L}^{-1} \mathrm{de}$ $\mathrm{CaCl}_{2}$, com $60 \mathrm{mg} \mathrm{L}^{-1}$ de P. Após a agitação, separaramse as fases sólida e líquida e, na solução de equilíbrio, foi determinada a concentração de Prem pelo método do ácido ascórbico e, posteriormente, foi feita a leitura em espectrofotômetro (Braga \& Defelipo, 1974).

Para os dados dos atributos químicos e físicos do solo, em cada camada, foi feita a avaliação da normalidade dos dados (teste de Lilliefors) e da homogeneidade das variâncias dos erros (teste de Cochran \& Barttlet). Posteriormente, os resultados foram submetidos à análise de variância com aplicação do teste $\mathrm{F}$, e os valores médios foram comparados entre si pelo teste de Tukey, a 5\% de probabilidade, com o auxílio dos programas estatísticos Saeg e Sisvar.

\section{Resultados e Discussão}

Em geral, a variabilidade observada em COT e MOL foi maior entre os sistemas de manejo do que entre as culturas agrícolas avaliadas (Tabela 1). É possível constatar que, à medida que a profundidade aumentou, o quadrado médio dos fatores de variação sistemas de manejo e culturas agrícolas 
apresentou tendência de redução, sendo que, na maior profundidade, apenas o Prem para o fator cultura agrícola apresentou significância. Em relação à interação sistema de manejo x cultura agrícola, destaca-se o efeito significativo para MOL e Prem nas camadas de 0,025-0,05 e 0,05-0,10 m.

Em relação à $\operatorname{MOL}(0,0-0,025 \mathrm{~m})$, na cultura do milho, o maior valor foi encontrado na cobertura com braquiária e os menores valores foram observados sob SPD com cultivo de cobertura de crotalária e no preparo convencional (Tabela 2). Na cultura da soja, apenas a área com braquiária diferiu das demais, com o maior valor. À profundidade de $0,025-0,050 \mathrm{~m}$, não foram observadas diferenças entre os sistemas de manejo para a cultura do milho. Na cultura da soja, a área sob pousio apresentou o menor valor.

O compartimento MOL pode ser considerado de dinâmica acelerada no solo (Leite, 2002). Portanto, sua manutenção é fundamental para a sustentabilidade dos sistemas agrícolas, uma vez que representa, em curto e médio prazo, alto potencial para ciclagem de nutrientes (Compton \& Boone, 2002). Ao avaliar o efeito da Gliricidia sepium sobre a disponibilidade dos nutrientes no solo, microclima e produtividade da cultura do milho em sistema agroflorestal no agreste paraibano, Pérez Marin et al. (2006) verificaram que a MOL do solo foi melhor indicador do que o COT, para detectar mudanças causadas pelo manejo da cobertura vegetal.

Tabela 1. Análise de variância para carbono orgânico total (COT), matéria orgânica leve ( MOL) e fósforo remanescente (Prem) em diferentes camadas de Latosso Vermelho, submetido a diferentes sistemas de manejo e cultivados com soja ou milho.

\begin{tabular}{|c|c|c|c|c|c|}
\hline \multirow[t]{2}{*}{ Atributo edáfico } & \multicolumn{3}{|c|}{ Fonte de variação } & \multirow{2}{*}{ CV erro 1} & \multirow{2}{*}{$\mathrm{CV}$ erro 2} \\
\hline & Sistema de manejo (A) & Cultura agrícola (B) & $\mathrm{A} \times \mathrm{B}$ & & \\
\hline & \multicolumn{5}{|c|}{ Camada do solo de $0,0-0,025 \mathrm{~m}$} \\
\hline COT & $6,26^{*}$ & $11,18^{*}$ & $2,88^{\mathrm{ns}}$ & 7,48 & 9,18 \\
\hline MOL & $39,50 *$ & $10,82 *$ & $4,04 * *$ & 14,33 & 23,13 \\
\hline Prem & $13,59^{*}$ & $5,00^{*}$ & $1,89^{\text {ns }}$ & 3,63 & 10,86 \\
\hline & \multicolumn{5}{|c|}{ Camada do solo de $0,025-0,05 \mathrm{~m}$} \\
\hline COT & $11,48^{*}$ & $1,32^{\text {ns }}$ & $0,26^{\mathrm{ns}}$ & 4,92 & 6,55 \\
\hline MOL & $26,00^{*}$ & $6,42 * *$ & $3,19 * *$ & 9,74 & 20,41 \\
\hline Prem & $7,71 *$ & $1,73^{\mathrm{ns}}$ & $4,75^{* *}$ & 4,99 & 5,22 \\
\hline & \multicolumn{5}{|c|}{ Camada do solo de $0,05-0,10 \mathrm{~m}$} \\
\hline COT & $7,55^{*}$ & $9,34 *$ & $0,60^{\text {ns }}$ & 4,8 & 5,37 \\
\hline MOL & $10,23 *$ & $3,00^{\text {ns }}$ & $7,17^{\text {ns }}$ & 22,65 & 23,31 \\
\hline Prem & $1,89^{\mathrm{ns}}$ & $2,76^{\mathrm{ns}}$ & $9,44 *$ & 7,36 & 7,23 \\
\hline \multicolumn{6}{|c|}{ Camada do solo de $0,10-0,20 \mathrm{~m}$} \\
\hline COT & $2,08^{\text {ns }}$ & $1,29^{\text {ns }}$ & $1,88^{\text {ns }}$ & 5,53 & 7,69 \\
\hline MOL & $3,06^{\mathrm{ns}}$ & $0,13^{\text {ns }}$ & $0,78^{\mathrm{ns}}$ & 32,81 & 34,34 \\
\hline Prem & $0,37^{\mathrm{ns}}$ & $6,65 * *$ & $1,86^{\mathrm{ns}}$ & & \\
\hline
\end{tabular}

${ }^{n}$ Não significativo. ${ }^{*} e^{* *}$ Significativo pelo teste $\mathrm{F}$ a 5 e a $1 \%$ de probabilidade, respectivamente.

Tabela 2. Médias dos atributos de solo avaliados em diferentes camadas de acordo com cinco sistemas de manejo - pousio, preparo convencional e sistema de plantio direto (SPD) com uso de braquiária (Urochloa brizantha) ${ }^{(1)}$.

\begin{tabular}{|c|c|c|c|c|c|}
\hline Cultura & SPD-braquiária & SPD-milheto & SPD-crotalária & Convencional & Pousio \\
\hline & \multicolumn{5}{|c|}{ Matéria orgânica leve $\left(\mathrm{g} \mathrm{kg}^{-1}\right)$ na camada $0,0-0,025 \mathrm{~m}$} \\
\hline Milho & $1,54 \mathrm{bA}$ & $1,10 \mathrm{aB}$ & $0,54 \mathrm{bC}$ & $0,80 \mathrm{aBC}$ & $1,10 \mathrm{aB}$ \\
\hline \multirow[t]{2}{*}{ Soja } & $2,14 \mathrm{aA}$ & $1,04 \mathrm{aB}$ & $1,13 \mathrm{aB}$ & $1,00 \mathrm{aB}$ & $1,24 \mathrm{aB}$ \\
\hline & \multicolumn{5}{|c|}{ Matéria orgânica leve $\left(\mathrm{g} \mathrm{kg}^{-1}\right)$ na camada $0,025-0,05 \mathrm{~m}$} \\
\hline Milho & $0,74 \mathrm{bA}$ & $0,76 \mathrm{aA}$ & $0,70 \mathrm{bA}$ & $0,80 \mathrm{aA}$ & $0,64 \mathrm{aA}$ \\
\hline \multirow[t]{2}{*}{ Soja } & $1,04 \mathrm{aA}$ & $0,90 \mathrm{aA}$ & $1,00 \mathrm{aA}$ & $0,90 \mathrm{aA}$ & $0,44 \mathrm{aB}$ \\
\hline & \multicolumn{5}{|c|}{ Matéria orgânica leve $\left(\mathrm{g} \mathrm{kg}^{-1}\right)$ na camada $0,05-0,10 \mathrm{~m}$} \\
\hline Milho & $0,36 \mathrm{aB}$ & $0,50 \mathrm{aAB}$ & $0,70 \mathrm{aA}$ & $0,30 \mathrm{aB}$ & $0,64 \mathrm{aA}$ \\
\hline \multirow[t]{2}{*}{ Soja } & $0,30 \mathrm{aB}$ & $0,56 \mathrm{aAB}$ & $0,71 \mathrm{aA}$ & $0,44 \mathrm{aB}$ & $0,60 \mathrm{aA}$ \\
\hline & \multicolumn{5}{|c|}{ Fósforo remanescente $\left(\mathrm{mg} \mathrm{kg}^{-1}\right)$ na camada $0,025-0,05 \mathrm{~m}$} \\
\hline Milho & $30,91 \mathrm{bC}$ & $32,86 \mathrm{aBC}$ & $37,21 \mathrm{aA}$ & $34,79 \mathrm{aAB}$ & $34,69 \mathrm{aAB}$ \\
\hline Soja & $36,06 \mathrm{aAB}$ & $34,12 \mathrm{aAB}$ & $37,71 \mathrm{aA}$ & $32,95 \mathrm{aB}$ & $33,35 \mathrm{aB}$ \\
\hline \multicolumn{6}{|c|}{ Fósforo remanescente $\left(\mathrm{mg} \mathrm{kg}^{-1}\right)$ na camada $0,05-0,10 \mathrm{~m}$} \\
\hline Milho & $31,23 \mathrm{bAB}$ & $29,48 \mathrm{bB}$ & $33,82 \mathrm{aAB}$ & $35,16 \mathrm{aA}$ & $29,86 \mathrm{bB}$ \\
\hline Soja & $36,13 \mathrm{aA}$ & $33,25 \mathrm{aA}$ & $33,84 \mathrm{aA}$ & $27,96 \mathrm{bB}$ & $34,53 \mathrm{aA}$ \\
\hline
\end{tabular}

${ }^{(1)}$ Médias seguidas de letras iguais, minúsculas nas colunas e maiúsculas nas linhas, não diferem entre si, pelo teste de Tukey, a 5\% de probabilidade. 
Em relação aos valores de Prem $(0,025-0,05$ m), observou-se que, independentemente da cultura, a área com crotalária apresentou os maiores valores (Tabela 2). Entretanto, esses valores na cultura do milho não diferiram estatisticamente dos observados nas áreas em pousio e em preparo convencional, enquanto, na cultura da soja, eles não diferiram dos observados nas áreas com braquiária e milheto. $\mathrm{Na}$ cultura do milho, a área com braquiária apresentou o menor valor, enquanto que, na soja, as áreas com menores valores foram aquelas que estiveram sob preparo convencional e pousio. Na camada de $0,05-0,10 \mathrm{~m}$ de profundidade, na cultura do milho, o maior valor de Prem foi observado na área sob preparo convencional, mas sem apresentar diferenças significativas das áreas com crotalária e braquiária. Na cultura da soja, a área sob preparo convencional apresentou os menores valores de Prem.

Os valores de COT e EstCOT não apresentaram correlação significativa em nenhuma profundidade avaliada. Para a maioria das profundidades, os valores de Prem e de MOL também não estiveram correlacionados (Tabela 3 ), com exceção da camada $0,0-0,025 \mathrm{~m}$, para o pousio, e da camada $0,05-0,10 \mathrm{~m}$, para o SPD com uso das três coberturas. O sistema de preparo convencional não mostrou correlação entre MOL e Prem, em nenhuma das camadas avaliadas.
Destaca-se a elevada correlação $\left(\mathrm{r}=0,78^{* *}\right)$ observada na área de SPD com crotalária. Esses resultados sugerem que a adoção de sistemas de manejo que contemplem a elevação dos teores de MOS, na forma de MOL, podem proporcionar melhor aproveitamento do uso de P pelas culturas. Essa possibilidade é amparada pelo fato de que ácidos orgânicos de baixo peso molecular podem bloquear sítios de adsorção do fosfato (Tirloni et al., 2009).

Com relação aos teores de COT, não foram observadas interações significativas entre os tratamentos (Tabela 1). Os sistemas de manejo, no entanto, apresentaram efeitos significativos sobre esses parâmetros em todas as camadas avaliadas, com exceção da mais profunda $(0,10-0,20 \mathrm{~m})$. Na camada $0,0-0,025 \mathrm{~m}$, o sistema com preparo convencional do solo apresentou os menores teores de COT, significativamente inferiores aos sistemas pousio e SPD com braquiária (Tabela 4). $\mathrm{Na}$ camada subsequente, os menores valores foram observados para SPD com milheto, e, na camada $0,05-0,10 \mathrm{~m}$, os sistemas pousio e SPD com crotalária apresentaram os menores teores de COT. Na camada 0,10-0,20 m, não houve diferenças entre sistemas de manejo.

Para EstCOT na camada $0,0-0,20 \mathrm{~m}$ de profundidade, não foi observada interação significativa entre culturas e sistemas de manejo, sendo verificado apenas diferença

Tabela 3. Coeficientes de correlação de Pearson $(n=8)$ entre os valores de matéria orgânica leve e de fósforo remanescente (Prem), nas diferentes camadas de solo estudadas, de acordo com cinco sistemas de manejo - pousio, preparo convencional e sistema de plantio direto (SPD) com uso de braquiária (Uruchloa brizantha), milheto (Pennisetum americanum) e crotalária (Crotalaria juncea) como planta de cobertura do solo.

\begin{tabular}{|c|c|c|c|c|c|}
\hline Camada de solo & SPD-braquiária & SPD-milheto & SPD-crotalária & SPD-convencional & Pousio \\
\hline $0,0-0,025 \mathrm{~m}$ & $0,09^{\text {ns }}$ & $-0,06^{\mathrm{ns}}$ & $0,04^{\mathrm{ns}}$ & $0,34^{\text {ns }}$ & $0,66^{* *}$ \\
\hline $0,025-0,05 \mathrm{~m}$ & $0,11^{\mathrm{ns}}$ & $-0,26^{\mathrm{ns}}$ & $0,12^{\text {ns }}$ & $0,06^{\mathrm{ns}}$ & $0,23^{\mathrm{ns}}$ \\
\hline $0,05-0,10 \mathrm{~m}$ & $0,58 *$ & $0,55^{*}$ & $0,78 * *$ & $0,31^{\mathrm{ns}}$ & $0,43^{\text {ns }}$ \\
\hline $0,10-0,20 \mathrm{~m}$ & $-0,36^{\mathrm{ns}}$ & $0,01^{\mathrm{ns}}$ & $-0,42^{\mathrm{ns}}$ & $-0,19^{\mathrm{ns}}$ & $-0,15^{\mathrm{ns}}$ \\
\hline
\end{tabular}

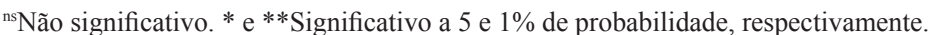

Tabela 4. Média dos valores de carbono orgânico total e de estoque de carbono nas diferentes profundidades de solo avaliadas, de acordo com cinco sistemas de manejo - pousio, preparo convencional e sistema de plantio direto (SPD) com uso de braquiária (Urochloa brizantha), milheto (Pennisetum americanum) e crotalária (Crotalaria juncea) como plantas de cobertura do solo - e culturas agrícolas ${ }^{(1)}$.

\begin{tabular}{|c|c|c|c|c|c|c|c|}
\hline \multirow[t]{2}{*}{ Camada de solo } & \multicolumn{5}{|c|}{ Sistema de manejo } & \multicolumn{2}{|c|}{ Cultura } \\
\hline & SPD-braquiária & SPD-milheto & SPD-crotalária & Convencional & Pousio & Milho & Soja \\
\hline & \multicolumn{7}{|c|}{ Carbono orgânico total $\left(\mathrm{g} \mathrm{kg}^{-1}\right)$} \\
\hline $0,0-0,025 \mathrm{~m}$ & $6,74 a$ & $6,08 \mathrm{ab}$ & $6,43 \mathrm{ab}$ & $5,69 \mathrm{~b}$ & $6,55 \mathrm{a}$ & $6,60 \mathrm{a}$ & $5,99 \mathrm{~b}$ \\
\hline $0,025-0,05 \mathrm{~m}$ & $5,99 \mathrm{a}$ & $5,07 \mathrm{~b}$ & $5,62 \mathrm{a}$ & $5,56 a$ & $5,63 \mathrm{a}$ & $5,63 \mathrm{a}$ & $5,50 \mathrm{a}$ \\
\hline $0,05-0,10 \mathrm{~m}$ & $4,87 \mathrm{ab}$ & $4,90 \mathrm{ab}$ & $4,57 \mathrm{~b}$ & $5,04 \mathrm{a}$ & $4,53 b$ & $4,66 b$ & $4,90 \mathrm{a}$ \\
\hline \multirow[t]{2}{*}{$0,10-0,20 \mathrm{~m}$} & $4,70 \mathrm{a}$ & $4,56 \mathrm{a}$ & $4,42 \mathrm{a}$ & $4,67 \mathrm{a}$ & $4,44 \mathrm{a}$ & $4,50 \mathrm{a}$ & $4,62 \mathrm{a}$ \\
\hline & \multicolumn{7}{|c|}{ Estoque de carbono orgânico $\left(\mathrm{Mg} \mathrm{ha}^{-1}\right)$} \\
\hline $0,0-0,20 \mathrm{~m}$ & $26,21 \mathrm{ab}$ & $27,00 \mathrm{a}$ & $25,51 b$ & $26,37 \mathrm{ab}$ & $25,61 b$ & $25,31 \mathrm{a}$ & $25,96 \mathrm{a}$ \\
\hline
\end{tabular}

${ }^{(1)}$ Médias seguidas de letras iguais na linha, para sistema de manejo e cultura, não diferem entre si, pelo teste de Tukey, a $5 \%$ de probabilidade. 
significativa entre os sistemas de manejo. O SPD com uso do milheto como planta de cobertura possibilitou maiores valores médios de estoque de carbono $(0,0-0,20 \mathrm{~m})$ em detrimento das áreas de crotalária e pousio (Tabela 4). Entretanto, não foram verificadas diferenças entre as áreas de braquiária e sistema convencional quando comparadas à cobertura de milheto.

No sistema convencional, os valores de estoque de carbono encontrados estão de acordo com o que se espera do revolvimento do solo, com a incorporação dos resíduos vegetais depositados na superfície do solo em camadas mais profundas. No SPD com milheto, a ausência do revolvimento do solo associado ao seu sistema radicular que é capaz de incorporar carbono em profundidade e de capturar nutrientes facilmente lixiviados (Foy, 1997) corroboram os maiores valores encontrados, estando também de acordo com Bayer et al. (2004), Wendling et al. (2005) e Loss et al. (2009).

Os resultados de estoque de carbono encontrados neste estudo são considerados baixos se comparados com outros trabalhos da literatura (Bayer et al., 2004; Wendling et al., 2005; Corbeels et al., 2006; Blanchart et al., 2007; Siqueira Neto et al., 2009). Entretanto, o acúmulo de $\mathrm{C}$ pode variar regionalmente devido às condições climáticas (Carvalho et al., 2010), ao tipo de solo (Bayer \& Mielniczuk, 1999), ao manejo aplicado e, principalmente, em função do tempo de implantação do SPD (Carvalho et al., 2009).

Comparando-se os valores de estoque de carbono deste trabalho com os encontrados por Conceição et al. (2005) verifica-se que sob o mesmo tipo de manejo, SPD com rotação de culturas, e mesma textura de solo, os estoque de carbono encontrados por Conceição et al. (2005) são todos inferiores aos observados neste trabalho.

\section{Conclusões}

1. A matéria orgânica leve é um indicador mais responsivo à interação dos efeitos dos sistemas de manejo e culturas agrícolas avaliadas, em comparação ao carbono orgânico total.

2. Em áreas sob plantio direto com uso de plantas de cobertura do solo, o aumento nos teores de matéria orgânica leve pode reduzir a adsorção de fósforo ao solo.

3. Sistemas de manejo que não envolvem revolvimento do solo favorecem o aumento do estoque de carbono orgânico nas camadas superficiais, enquanto o sistema de manejo com preparo convencional e o plantio direto, com uso do milheto como planta de cobertura, propicia a incorporação mais profunda do carbono.

\section{Agradecimentos}

Ao Conselho Nacional de Desenvolvimento Científico e Tecnológico e à Fundação Agrisus, pelo apoio financeiro.

\section{Referências}

ALMEIDA, J.A.; TORRENT, J.; BARRÓN, V. Cor do solo, formas do fósforo e adsorção de fosfato em Latossolos desenvolvidos de basalto do extremo-sul do Brasil. Revista Brasileira de Ciência do Solo, v.27, p.985-1002, 2003.

ALVAREZ V., V.H.; FONSECA, D.M. da. Definição de doses de fósforo para determinação da capacidade máxima de adsorção de fosfatos e para ensaios em casa de vegetação. Revista Brasileira de Ciência do Solo, v.14, p.49-55, 1990.

ANDERSON, J.M.; INGRAM, J.S.I. Tropical soil biology and fertility: a handbook of methods. Wallingford: CAB International, 1989. $171 \mathrm{p}$

BAYER, C.; MARTIN-NETO, L.; MIELNICZUK, J.; PAVINATO, A. Armazenamento de carbono em frações lábeis da matéria orgânica de um Latossolo Vermelho sob plantio direto. Pesquisa Agropecuária Brasileira, v.39, p.677-683, 2004.

BAYER, C.; MIELNICZUK, J. Dinâmica e função da matéria orgânica. In: SANTOS, G. de A.; CAMARGO, F.A. de O. (Ed.). Fundamentos da matéria orgânica do solo: ecossistemas tropicais e subtropicais. Porto Alegre: Genesis, 1999. p.1-26.

BERNOUX, M.; CERRI, C.C.; CERRI, C.E.P.; SIQUEIRA NETO, M.; METAY, A.; PERRIN, A.; SCOPEL, E.; BLAVET, D.; PICCOLO, M.C. Influence du semis direct avec couverture végétale sur la séquestration du carbone et l'érosion au Brésil. Bulletin Du Réseau Érosion, v.23, p.323-337, 2004.

BERTIN, E.G.; ANDRIOLI, I.; CENTURION, J.F. Plantas de cobertura em pré-safra ao milho em plantio direto. Acta Scientiarum. Agronomy, v.27, p.379-386, 2005.

BLANCHART, E.; BERNOUX, M.; SARDA, X.; SIQUEIRA NETO, M.; CERRI, C.C.; PICCOLO, M.C.; DOUZET, J.M.; SCOPEL, E.; FELLER, C. Effect of direct seeding mulch-based systems on soil carbon storage and macrofauna in Central Brazil. Agriculturae Conspectus Scientificus, v.72, p.81-87, 2007.

BOER, C.A.; ASSIS, R.L. de; SILVA, G.P.; BRAZ, A.J.B.P.; BARROSO, A.L. de L.; CARGNELUTTI FILHO, A.; PIRES, F.R. Ciclagem de nutrientes por plantas de cobertura na entressafra em um solo de cerrado. Pesquisa Agropecuária Brasileira, v.42, p.1269-1276, 2007. 
BRAGA, J.M.; DEFELIPO, B.V. Determinação espectrofotométrica de fósforo em extratos de solo e material vegetal. Revista Ceres, v.21, p.73-85, 1974.

BRANCALIÃO, S.R.; MORAES, M.H. Alterações de alguns atributos físicos e das frações húmicas de um Nitossolo Vermelho na sucessão milheto-soja em sistema plantio direto. Revista Brasileira de Ciência do Solo, v.32, p.393-404, 2008.

CARVALHO, J.L.N.; AVANZI, J.C.; SILVA, M.L.N.; MELLO, C.R. de; CERRI, C.E.P. Potencial de sequestro de carbono em diferentes biomas do Brasil: uma revisão de literatura. Revista Brasileira de Ciência do Solo, v.34, p.277-289, 2010.

CARVALHO, J.L.N.; CERRI, C.E.P.; FEIGL, B.J.; PICOLLO, M.C.; GODINHO, V.P.; CERRI, C.C. Carbon sequestration in agricultural soils in the Cerrado region of the Brazilian Amazon. Soil and Tillage Research, v.103, p.342-349, 2009.

CLAESSEN, M.E.C. (Org.). Manual de métodos de análise de solo. 2.ed. rev. atual. Rio de Janeiro: Embrapa-CNPS, 1997. 212p. (Embrapa-CNPS. Documentos, 1).

COMPTON, J.E.; BOONE, R.D. Soil nitrogen transformations and the role of light fraction organic matter in forest soils. Soil Biology and Biochemistry, v.34, p.933-943, 2002.

CONCEIÇÃO, P.C.; AMADO, T.J.C.; MIELNICZUK, J.; SPAGNOLLO, E. Qualidade do solo em sistemas de manejo avaliada pela dinâmica da matéria orgânica e atributos relacionados. Revista Brasileira de Ciência do Solo, v.29, p.777-788, 2005.

CORBEELS, M.; SCOPEL, E.; CARDOSO, A.; BERNOUX, M.; DOUZET, J.M.; SIQUEIRA NETO, M.S. Soil carbon storage potential of direct seeding mulch-based cropping systems in the Cerrados of Brazil. Global Change Biology, v.12, p.1773-1787, 2006.

ELLERT, B.H.; BETTANY, J.R. Calculation of organic matter and nutrients stored in soils under contrasting management regimes. Canadian Journal of Soil Science, v.75, p.529-538, 1995.

FONTANA, A.; PEREIRA, M.G.; SALTON, J.C.; LOSS, A.; CUNHA, T.J.F. Fósforo remanescente e correlação com as substâncias húmicas em um Latossolo Vermelho sob diferentes sucessões de cultura em plantio direto. Revista Brasileira de Agrociência, v.14, p.1-6, 2008.

FOY, C.D. Tailoring plants to fit problem soils: progress and problems for future research. In: MONIZ, A.C.; FURLANI, A.M.; SHAFFERT, R.E. (Ed.). Plant-soil interactions at low pH: sustainable agriculture and forestry production. Campinas: Brazilian Soil Science Society, 1997. p.55-57.

IBIA, T.O.; UDO, E.J. Phosphorus forms and fixation capacity of representative soils in Akwa Ibom State of Nigeria. Geoderma, v.58, p.95-106, 1993.

JANZEN, H.H.; CAMPBELL, C.A.; BRANDT, S.A.; LAFOND, G.P.; TOWNLEY-SMITH, L. Light-fraction organic matter in soils from long-term crop rotations. Soil Science Society of America Journal, v.56, p.1799-1806, 1992.

LEITE, L.F.C. Compartimentos e dinâmica da matéria orgânica do solo sob diferentes manejos e sua simulação pelo modelo Century.
2002. 142p. Tese (Doutorado) - Universidade Federal de Viçosa, Viçosa.

LOSS, A.; PEREIRA, M.G.; SCHULTZ, N.; ANJOS, L.H.C. dos; SILVA, E.M.R. Atributos químicos e físicos de um Argissolo Vermelho-Amarelo em sistema integrado de produção agroecológica. Pesquisa Agropecuária Brasileira, v.44, p.68-75, 2009.

MORETI, D.; ALVES, M.C.; VALÉRIO FILHO, W.V.; CARVALHO, M. de P. e. Atributos químicos de um Latossolo Vermelho sob diferentes sistemas de preparo, adubações e plantas de cobertura. Revista Brasileira de Ciência do Solo, v.31, p.167-175, 2007.

NOVAIS, R.F. de; SMYTH, T.J. Fósforo em solo e planta em condições tropicais. Viçosa: UFV, 1999. 399p.

PÉREZ MARIN, A.M.; MENEZES, R.S.C.; SILVA, E.D.; SAMPAIO, V.deS.B. Efeito da Gliricidia sepium sobre nutrientes do solo, microclima e produtividade do milho em sistema agroflorestal no Agreste Paraibano. Revista Brasileira de Ciência do Solo, v.30, p.555-564, 2006.

SANO, E.E.; FERREIRA, L.G.; ASNER, G.P.; STEINKE, E.T. Spatial and temporal probabilities of obtaining cloud-free Landsat images over the Brazilian tropical savanna. International Journal of Remote Sensing, v.28, p.2739-2752, 2007.

SANO, E.E.; ROSA, R.; BRITO, J.L.S.; FERREIRA, L.G. Mapeamento semidetalhado do uso da terra do Bioma Cerrado. Pesquisa Agropecuária Brasileira, v.43, p.153-156, 2008.

SANTOS, H.G. dos; JACOMINE, P.K.T.; ANJOS, L.H.C. dos; OLIVEIRA, V.A. de; OLIVEIRA, J.B. de; COELHO, M.R.; LUMBRERAS, J.F.; CUNHA, T.J.F. (Ed.). Sistema brasileiro de classificação de solos. Rio de Janeiro: Embrapa Solos, 2006. 306p.

SIQUEIRA NETO, M.; PICCOLO, M. de C.; SCOPEL, E.; COSTA JUNIOR, C. da; CERRI, C.C; BERNOUX, M. Carbono total e atributos químicos com diferentes usos do solo no Cerrado. Acta Scientiarum. Agronomy, v.31, p.709-717, 2009.

SISTI, C.P.J.; SANTOS, H.P. dos; KOHHANN, R.; ALVES, B.J.R.; URQUIAGA, S.; BODDEY, R.M. Change in carbon and nitrogen stocks in soil under 13 years of conventional or zero tillage in southern Brazil. Soil and Tillage Research, v.76, p.39-58, 2004.

TIRLONI, C.; VITORINO, A.C.T.; NOVELINO, J.O.; TIRLONI, D.; COIMBRA, D.S. Disponibilidade de fósforo em função das adições de calagem e de um bioativador do solo. Ciência e Agrotecnologia, v.33, p.977-984, 2009.

TORRES, J.L.R.; PEREIRA, M.G.; FABIAN, A.J. Produção de fitomassa por plantas de cobertura e mineralização de seus resíduos em plantio direto. Pesquisa Agropecuária Brasileira, v.43, p.421-428, 2008.

WENDLING, B.; JUCKSCH, I.; MENDONÇA, E. de S.; NEVES, J.C.L. Carbono orgânico e estabilidade de agregados de um Latossolo Vermelho sob diferentes manejos. Pesquisa Agropecuária Brasileira, v.40, p.487-494, 2005.

Recebido em 17 de maio de 2009 e aprovado em 11 de janeiro de 2010

Pesq. agropec. bras., Brasília, v.45, n.5, p.508-514, maio 2010 